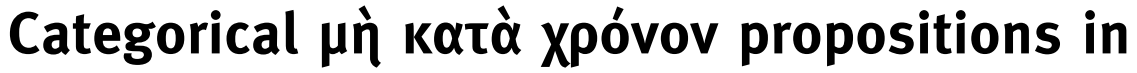 Alexander of Aphrodisias' modal syllogistic
}

\begin{abstract}
In this paper I deal with Alexander of Aphrodisias' theory of categori-

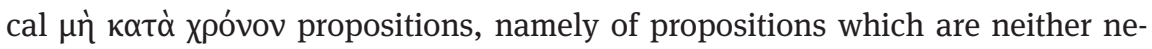
cessity nor contingency propositions, but which are true not only at a certain instant in time. I argue that these propositions are true at least at two instants in time, but their presentation does not commit Alexander to a revision of his general semantic scheme for modal propositions, in which he showed that categorical propositions are not necessity propositions, and thus cannot be true at every instant in time. In the last section, I shall argue that Alexander's presen-

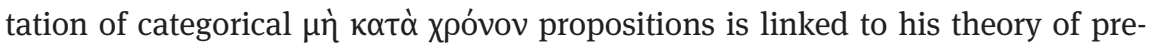
dication and that such a semantic framework may explain the apparently difficult classification of this set of propositions.
\end{abstract}

Keywords: Aristotle - Alexander of Aphrodisias - late ancient commentators modal logic - temporal semantics - syllogism - modality - predicative relation

Luca Gili: Katholieke Universiteit Leuven - De Wulf-Mansion, Centre, Hoger Instituut voor Wijsbegeerte, Kardinaal Mercierplein 2, Leuven, Vlams Brabant, 3000 Belgium

Fonds Wetenschappelijk Onderzoek - Vlaanderen, Egmontstraat 5, Brussel, Brussel 1000, Belgium; E-mail: luca.gili@hiw.kuleuven.be, luca.gili1987@gmail.com

The aim of this paper is to outline Alexander of Aphrodisias' theory of categori-

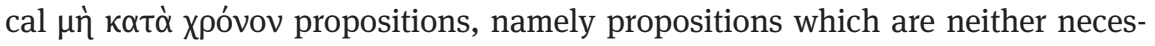
sity nor contingency propositions, but which are true not only at a certain instant in time. ${ }^{1}$ This kind of proposition is quite puzzling at first glance, because

o A detailed presentation of Alexander's works may be found in Moraux 2001, while Sharples 1987 represents a synthetic and stimulating exposition of his philosophy. Alexander has been rediscovered during recent decades and, among the general new appreciation of late ancient philosophy, the prominent figure of the commentator of Aphrodisias has attracted the attention of many scholars. However, his logical thought has been in some sense neglected, and literature on this topic is not as vast as that concerning psychology or metaphysics. The only comprehensive study of Alexander's logic is still Volait 1907, but this book is nothing more than a clever paraphrase of some key passages of Alexander's commentary on Aristotle's Prior Analytics; Lee 1984 compares Alexander's conception of logic with those of Philoponus and Ammonius, but does not touch his modal syllogistic; Flannery 1995 is a tripartite essay, concerning 
Alexander has a rigid classification of all propositions, which can figure as premises and conclusions of a syllogism: he divides them into three kinds, depending on the time in which it would have been true to say that the predicate holds of the subject. The three kinds are as follows:

a) necessity propositions, if the predicate holds always of the subject;

b) plain contingency propositions (according to a more general meaning of "contingency"), if the predicate does not always hold of the subject. Among them we find

b.1) categorical propositions, if the predicate holds now of the subject;

b.2) genuine contingency propositions, if the predicate does not now hold of the subject. $^{2}$

Alexander's theory of logical matter and logical form, of हैk $\theta \varepsilon \sigma \iota \varsigma$, and of mixed necessity syllogisms; Gili 2011a deals with Alexander's categorical and modal syllogistic in the commentary on Prior Analytics, whilst Gili 2011b aims at tracing some of the possible sources for a few claims made by Alexander in the context of his exposition of categorical syllogistic; Gili 2012 deals with Alexander's semantics for modal syllogistic, and the present paper is designed to deepen the conclusions reached in that paper.

1 Cf. in Pr. Anal. p. 25, 1. 26-p. 26, 1. 22: With 'every proposition' one has to understand 'predicative'. For Aristotle is here dealing only with propositions and syllogisms of this sort - they are the ones of which he has given an account. Now in every predicative proposition a term is predicated of a term either affirmatively or negatively, i.e. as holding of the subject or not holding of it. Of those terms which hold of something, some hold always while others sometimes hold and sometimes do not hold. If what is said to hold holds always and is taken as holding always, then the proposition is a true necessary affirmative. A true necessary negative is a proposition in which what by nature never holds of something is taken never to hold of it. If the predicate does not always hold of the subject, then if it holds of it at the present moment, the proposition which marks this is a true categorical affirmative; and in the same way, a true categorical negative is a proposition which says that what does not now hold does not hold. If the predicate does not hold of the subject at the present moment, although it is possible for it to hold, and if it is taken in this way, i.e. as being possible, then the proposition is a true contingent affirmative; and a proposition which says of something which either holds or does not hold but can both hold and not hold, that it is contingent for it not to hold, is a true contingent negative.

Such propositions are false when they mark something as having a mode which it does not in fact have. For since propositions make clear that what is meant by them holds, the propositions themselves, if they are assimilated to the mode of what they mean, correspond to the way in which those items hold.

Further, everything which holds of something either is inseparable from it and holds of it in its own right, or else is necessary, and if it is separable, contingent. If a contingent proposition means what is already present, it is categorical; if it means either what has been separated or what is not yet present but can hold, then it is contingent in the specific sense. (transl. BarnesBobzien-Flannery-Ierodiakonou 1991, 79-80, slightly modified).

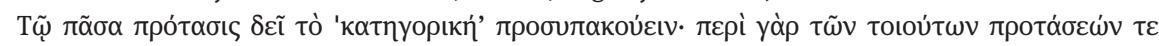


Alexander presents this classification when he speaks of propositions which can, in general, figure in a syllogism. If categorical propositions are the propositions in which the predicate holds of the subject at the present instant of time, but cannot hold at every instant of time (otherwise they would be necessity pro-

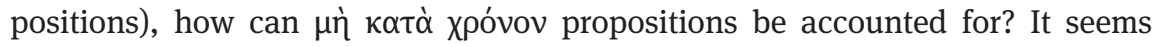
indeed that the scheme outlined by Alexander in in Pr. Anal. p. 25, 1. 26-p. 26, 1. 22 makes no room for this subset of categorical propositions. However, later in his commentary, it is possible to see that Alexander tries to reshape the definitions he has given in this opening scheme, without completely abandoning it. A clear test case for this involves genuine contingency propositions: according to Alexander, a contingency proposition like

a) A contingently holds of $B$

means that A does not always hold of B and that A does not now hold of B (cf. in Anal. Pr. p. 26, 1l. 7-12:

"If the predicate does not always hold of the subject, then if it holds of it at the present moment, the proposition which marks this is the true categorical affirmative; and in the same way, a true categorical negative is a proposition which says that what does not now hold does not hold. If the predicate does not hold of the subject at the present moment, although it is possible for it to hold, and if it is taken in this way, i.e. as being possible, then the proposition is a true

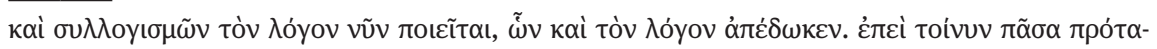

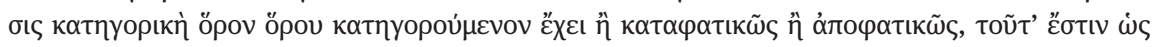

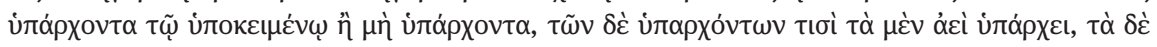

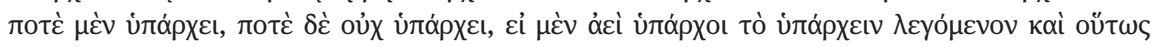

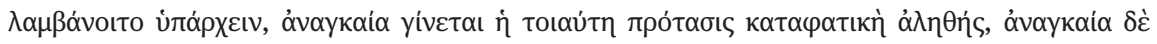
ár

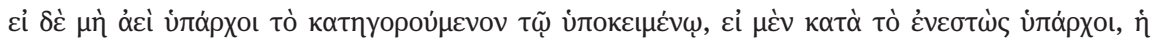

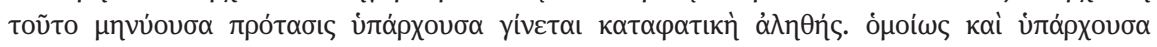

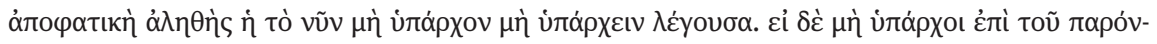

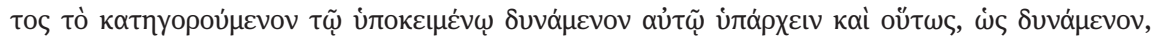

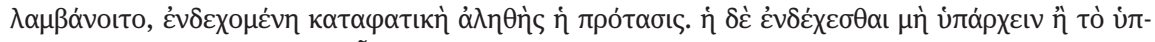

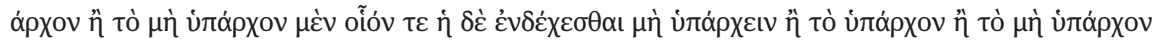

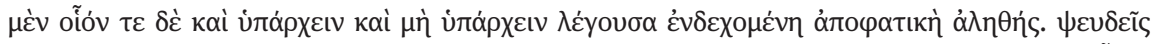

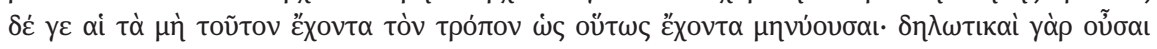

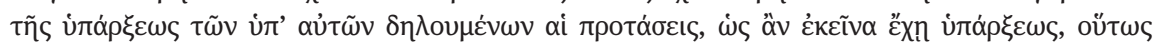

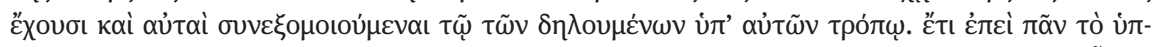

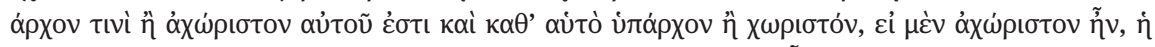

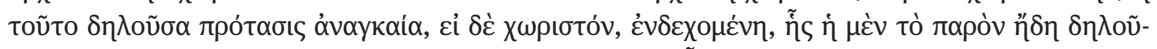

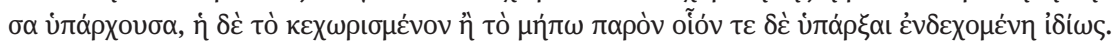


contingent affirmative” (transl. Barnes-Bobzien-Flannery-Ierodiakonou, 1991, 79, slightly modified). ${ }^{3}$

Prima facie, the straightforward reading of this explanation is that there is an instant of time $t$, different from the present, such that A holds of B at $t$. As is well known, if contingency means that the event $E$ is contingent if and only if $E$ happens in the future, even though it is not yet the case, we are faced with the so-called statistical interpretation of contingency. This interpretation has been proposed for Aristotle by J. Hintikka, ${ }^{4}$ and, on the basis of Alexander's scheme of modal proposition, one might be tempted to attribute this theory also to the commentator of Aphrodisias. However, this statistical interpretation of modalities is hardly compatible with Aristotle's and Alexander's rejection of determinism, since it implies that, if an event is possible, it will necessarily happen. Alexander was probably aware of this problem, generated by his description of modalities - he knew that the Stoics had a similar scheme for modalities ${ }^{5}$ and that they consistently upheld a deterministic interpretation of reality. It is thus not surprising to find in Alexander's commentary an attempt to reshape and soften this introductory semantic scheme for modal propositions. In the case of contingency propositions, for example, he affirms that they speak about the future inherence of the predicate to the subject that figures in them, but he adds also that such an inherence may fail to happen, due to external causes. ${ }^{6}$ In this way, Alexander avoids endorsing the deterministic principle of plenitude, which seemed to follow from his first rough definition of contingency. The non-deterministic redefinition of contingency, which makes room for possibilities which fail to happen, does not mean for Alexander that the scheme of in Pr. Anal. p. $25,1.26-$ p. $26,1.22$ is completely inadequate: contingency propositions must simply be defined as propositions in which the predicate, which actually does

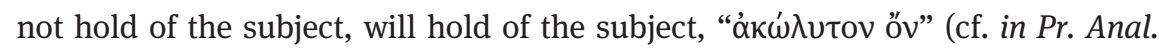
p. 184, 11. 11-12).

This solution, however, seems to be not particularly helpful, in order to ex-

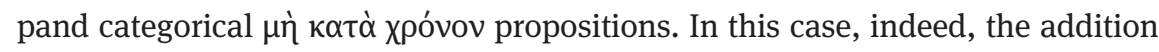

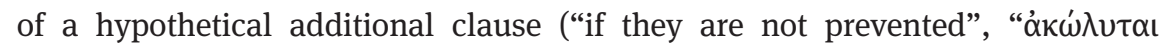

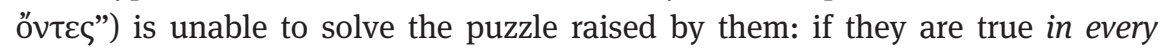

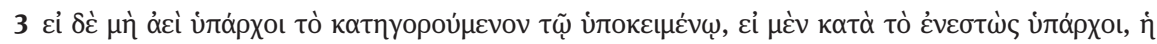

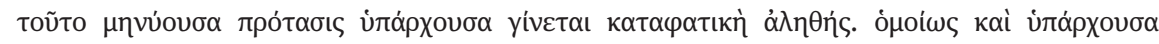

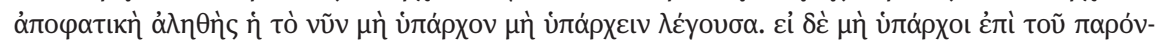

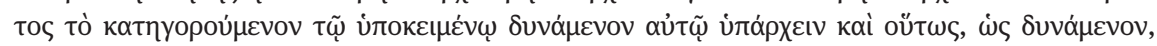

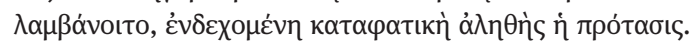

4 Cf. Hintikka 1973.

5 Cf. Frede 1974, 107-110, Bobzien 1986, 46-49; Bobzien 1998, 98-99.

6 Cf. in Pr. Anal. p. 184, 11. 10-18. 
instant of time, they must be necessity propositions, and if we were to say that they are necessity propositions, if they are not prevented, they are still hypothetical necessity propositions; but Alexander clearly distinguishes them from necessity propositions. On the other hand, if they are mere categorical proposi-

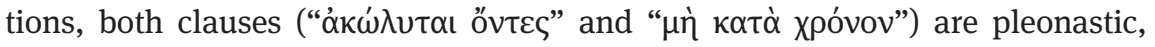
because categorical propositions are, by definition, true at the present instant in time. As a consequence, we may understand why Alexander did not add any clauses to his previous definition of plain contingency proposition, in order to

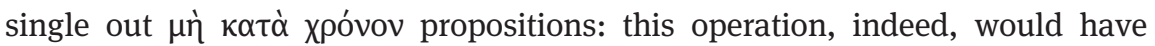
been unhelpful in expanding their semantic status. In other words, it is clear that Alexander wants to reshape his rough semantic scheme for modal propositions, in order to solve some philosophical problems that it may generate; but

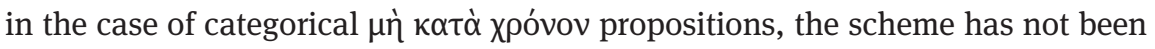
altered, even though a redefinition of the scheme would have been needed to show properly what they are: as a matter of fact, Alexander did not furnish such a redefinition of his scheme in the extant part of his commentary on Prior Analytics. What then is the status of these propositions?

\section{The puzzle}

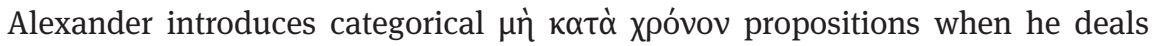
with the rather complicated proofs for the validity of mixed contingency syllogisms. $^{7}$

0 As is well known, Aristotle's modal syllogistic has been a matter of dispute since Theophrastus' philosophical activity. Among modern scholars, Becker 1933 claimed its inconsistency, because he thought that while the rules for modal conversions are valid only with a de dicto reading of the modal operator, modal mixed syllogisms are valid with a de re reading of the modal operator. Łukasiewicz 1957 and Hintikka 1959 also upheld inconsistency of modal mixed syllogisms as expanded by Aristotle. The first attempt to accept Aristotle's modal claims may be found in McCall 1963, who took as axioms Aristotle's valid moods and axiomatically rejected the invalid combinations (analogously Johnson 1989 and Schmidt 1989 develop ad hoc models that satisfy all and only the valid formulae of Aristotle's system); Wieland 1966, 1972, and 1975 tries to justify Aristotle's theory on some textual considerations (he sharply distinguished between mere categorical propositions, and non-modal propositions, which figure in mixed modal syllogisms). Sainati 1981 and 1983 distinguishes between two types of modal propositions: one convertible, and one which can figure as a premise of a mixed valid syllogism, though it is not convertible. Since Patterson 1989, scholars have tried to give a philosophical justification to Aristotle's apparently conflicting modal assumptions (cf. also Patterson 1995, Thom 1996, Thom 2003, Mariani 2005): according to Patterson, Aristotle's semantics and theory of predica- 
Aristotle thinks that Barbara XQ-M is a valid imperfect syllogism: ${ }^{8}$

(1) A is said of all B

(2) B is contingently said of all C

Therefore (3) A is possibly said of all C.

In order to prove that (3) necessarily follows from (1) and (2), Aristotle presents a proof similar in its structure to the reduction ad impossibile. He builds up a syllogism with the contradictory of (3) as a major premise and with a categorical minor premise, which has the same subject and the same predicate as premise (2). Thus we have a valid Bocardo NX-X:

(a) A is necessarily not said of some C (premise which contradicts (3))

(b) B is said of all C (premise (2) turned into a categorical premise)

Therefore (c) A is not said of some B.

Since (c) contradicts (1), it is necessary to reject the assumption, under which it has been possible to infer (c). With the rejection of (a), we are entitled to consider its contradictory proposition to be true, namely (3). Hence (3) follows from (1) and (2) and Barbara XQ-M is a valid syllogism. This proof is valid, if we accept that from (2) it is possible to infer (b), but this is rather controversial. Aristotle says that if B contingently belongs to all $\mathrm{C}$, then it is false, but not impossible, that B belongs to all $\mathrm{C}$. Aristotle thinks that from a false but not impossible assumption (namely, that B actually belongs to all $\mathrm{C}$ ) may follow something which is false, but cannot follow anything which is impossible. Now, since (c) is an impossible conclusion (because it contradicts premise (1) of the first syllogism), it cannot be derived from the (false) assumption that B (actually) belongs to all $\mathrm{C}$. Hence, the major premise of the auxiliary syllogism ("A is necessarily not said of some C") must be rejected. ${ }^{9}$ This exposition of mine may

tion (on which see Mignucci 1996) are the grounds upon which modal syllogistic has been built up. Following this stream of studies, Malink 2006 proposed a very persuasive reconstruction of the whole modal syllogistic, which is able to give a philosophical and textual explanation of the assumptions of a logical modal that validates all and only the formulae that Aristotle accepts, and rejects all and only the formulae that Aristotle rejects.

1 Cf. Pr. Anal. A, 15, 34 a34-b2. As is well known, modern commentators distinguish two kinds of contingency in Aristotle: one-sided possibility (usually designated with M: "Mp" means that $p$ is possible) and two-sided possibility (labeled with $\mathrm{Q}$ : " $\mathrm{Q} p$ " means that both $p$ and not- $p$ are possible): in the following pages I will used these common labels, when I interpret Alexander's and Aristotle's ideas. With the letter ' $N$ ' I refer to a necessity premise, whilst ' $\mathrm{X}$ ' stands for a categorical premise, where there is no modal operator.

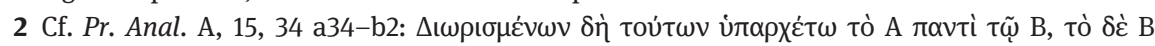

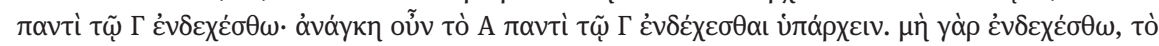


be seen as a paraphrase of Aristotle's exposition, but his precise meaning is not clear. Many commentators suggest that Aristotle tries to prove the validity of Barbara XQ-M with a reductio ad absurdum. ${ }^{10}$ It may be questioned, of course, whether Aristotle's argument is sound: Albrecht Becker, for example, claimed that Aristotle must suppose that if $\mathrm{A}, \mathrm{B}$ and $\mathrm{C}$ are propositions, if the conjunction of $\mathrm{A}$ and $\mathrm{B}$ is not compossible with $\mathrm{C}$, and $\mathrm{B}$ is compossible with $\mathrm{C}$, then $\mathrm{A}$ must not be compossible with C. But this rule is completely false, as Becker stresses. ${ }^{11}$ Hence, Aristotle's proof is unsound and it is impossible to admit the validity of Barbara XQ-M on these grounds. I am inclined to think that Becker's claim is right, but for the present purpose of this paper this aspect is not essential: Alexander, indeed, seems to endorse the rule that Becker (rightly) rejects. ${ }^{12}$

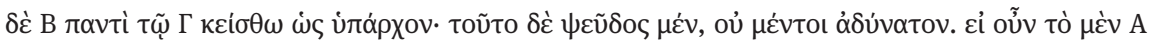

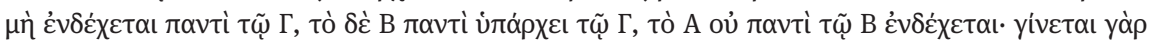

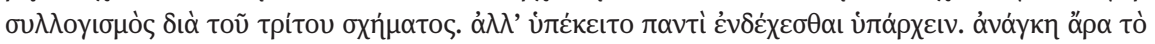

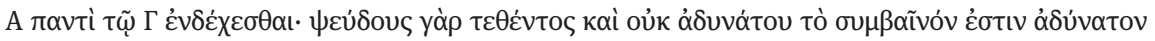
("since we have clarified these points, let $A$ belong to every $B$, and $B$ be possible for every $C$ : it is necessary that $A$ should possibly belong to every $C$. Suppose that this is not possible, but assume that $B$ belongs to every $C$ : this is false but not impossible. If then $A$ is not possible for every $C$ but $B$ belongs to every $C$, then $A$ is not possible for every $B$; for a syllogism is formed in the third figure. But it was assumed that $A$ possibly belonged to every $B$. It is necessary then $A$ is possible for every $C$. For though the assumption we made is false and not impossible, the conclusion is impossible", transl. Barnes 1984, 55, slightly modified).

3 Cf. W. D. Ross's comments in Pr. Anal., 339; Mignucci 1969, 324-325. Striker 2009, 146-147 rejects this interpretation (I share her conclusions).

4 Cf. Becker 1933, 52-54. The same remark has been made by Tredennick 1938, 270, note d; Striker 2009, 146 also suggests that Aristotle has not properly proved the validity of a mood Barbara XQM (or XQQ):

"The proof has the following steps:

AaB premiss

$\mathrm{Ba}_{\mathrm{Q}} \mathrm{C}$ premiss

$\mathrm{Ao}_{\mathrm{N}} \mathrm{C}$ hypothesis; contradictory of the expected conclusion

$\mathrm{BaC}$ hypothesis; "false but not impossible"

$\mathrm{Ao}_{\mathrm{N}} \mathrm{B}$ from (3) and (4) by Bocardo NXN

(5) contradicts (1), and Aristotle seems to infer that (3) is impossible relative to the premisses, since (4) - which was assumed to be possible - combined with (3) yields the impossible conclusion (5). But since (5) was derived from (3) in combination with (4), which is logically independent of, though compatible with, the premisses, all that his proof can show so far is that (3) cannot be true if both the premisses and (4) are true".

5 Cf. In Pr. Anal. p. 185, 11. 21-25. The same opinion has been shared by Philoponus (cf. Phil. In Pr. Anal. p. 173, 1l. 3-16), by Albert the Great (In Anal. Pr. I Paraphrasis, Tract. iv, caput VII, in B. Alberti Magni, Opera omnia, Volumen Primum (Logicae Prima Pars), cura ac labore A. Borgnet, Paris, Vivès, 1890, 551-554), by Maier 1900, 139 and by Mignucci 1969, 325. 
Alexander closely follows Aristotle's exposition and only specifies that when Aristotle presents (c), ${ }^{13}$ he does not consider (c) to be a contingency proposition, even though his expression could be interpreted in this way too: Aristotle, according to Alexander, is rather using the particular sense of contingency which is the categorical (see in Pr. Anal. p. 186, 11. 23-25). This presentation of Aristotle's thesis is puzzling within the framework of Alexander's temporal semantics for at least one reason: it is problematic to change a genuine contingency proposition into a categorical proposition, and, at the same time, to assume that the two propositions have the same truth value; however, in the auxiliary Bocardo NX-X, the minor premise seems to rely on such an (implicit) assumption.

Alexander tries to avoid this difficulty by claiming that, if it is true that

(i) it is contingent that $p\left(a t t_{k}\right)$

then it is false, but not impossible to say that

(ii) $p\left(a t t_{k}\right)$

Alexander adds that even if $p\left(a t t_{k}\right)$ is false, from that proposition there may not follow anything impossible. This is crucial for his purpose, as we shall see. Aristotle has indeed stated the following thesis (cf. Pr. Anal. A, 15, 34 a10-15):

(iii) if " $\beta$ " follows from " $\alpha$ ", then also "it is contingent that $\beta$ " follows from "it is contingent that $\alpha$ "

According to Alexander, this thesis implies that if " $\alpha$ " is a false, but not impossible proposition, and if " $\beta$ " follows from " $\alpha$ ", also “ $\beta$ " will not be impossible (cf. in Pr. Anal. p. 185, 11. 10-31). In sum, if one of the premises of a given syllogism is false but not impossible, the conclusion must likewise be false, but not impossible. Alexander thinks that the minor premise of Bocardo $\mathrm{NX}-\mathrm{X}$ is false, because it assumes that the predicate holds of the subject, while it does not hold yet; but this proposition is not impossible, since contingency premise (2), from which premise (b) has been derived, states, on the contrary, that the predicate can hold of the subject. As a consequence, the conclusion of Bocardo $\mathrm{NX}-\mathrm{X}$ is also false, but not impossible. Therefore, this conclusion may contradict the major premises of Barbara XQ-M. Unfortunately, this solution is not sufficient to solve the puzzle raised by the proof of the validity of Barbara XQ-M. This problem will be clearer if one rewrites the two syllogisms avoiding the opaque modal operators and replaces them with a reference to time - Alex-

13 Cf. Pr. Anal. A, 15, 34 a39. 
ander's semantics, indeed, allow us to make and suggest making this reformulation. Let us consider firstly Barbara XQ-M:

(1) B is said of all A at t

(2) C is contingently said of all $\mathrm{B}$ at $t_{1}$

Therefore (3) $\mathrm{C}$ is contingently said of all A at $t_{1} \cdot{ }^{14}$

According to the definition of contingency, "A is contingently $\mathrm{B}$ at $t_{1}$ " if it is true that " $\mathrm{A}$ is $\mathrm{B}$ at $t_{x>1}$ ". ${ }^{15}$ Hence, assuming that $t_{2}>t_{1}$, it is possible to rewrite the entire syllogism in this way:

(1) B is said of all A at $t_{1}$

$\left(2^{\prime}\right)$ C is said of all B at $t_{2}$

Therefore ( $\left.3^{\prime}\right) \mathrm{C}$ is said of all A at $t_{2}$.

Similarly Bocardo NX-X will be translated in the following way:

(a) C is not said of some $A_{\text {for every } x}$, at $t_{x}$

(b) $\mathrm{C}$ is said of all B at $t_{2}$ (premise (2'))

Therefore (c) B is not said of some A at $t_{2}$.

The puzzle arises from the fact that Bocardo NX-X is straightforwardly true, but (c) no longer contradicts the major premise (1) of Barbara XQ-M, which is therefore no longer validated by such a proof.

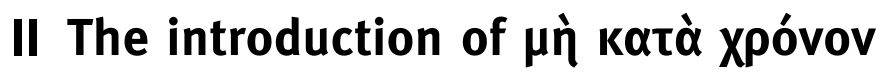 propositions}

In order to solve the puzzle, Alexander reflects on the observation made by Aristotle about the major categorical premise of Barbara XQ-M. The Stagirite said that the major premise must be considered not as referring to only one instant of time, namely to the present, but simpliciter, otherwise it would have been impossible to infer the conclusion of such syllogisms (cf. Pr. Anal. A, 15, 34 b718). With the help of examples, Aristotle explains why there would be no syllogism if the major categorical premise of Barbara XQ-M is true only for an instant in time. It is possible that in a certain instant all moving things are men;

14 Following Alexander, I make no distinction between one-sided and two-sided possibility in the presentation of this syllogism.

15 It is necessary also to assume that there are no external causes which prevent the realization of the possibility expressed by the contingency proposition. 
but it is contingent that all horses are in motion. By virtue of Barbara XQ-M, it would follow that all horses are contingently men, but this is impossible. Therefore, what the major categorical premise must not be is clear, according to Aris-

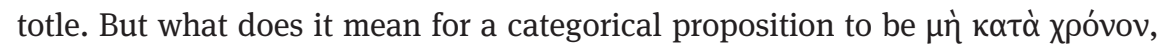
i.e. simpliciter true, though not necessarily true?

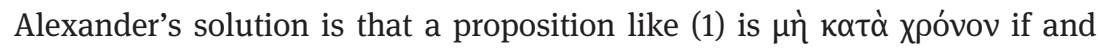
only if it is true both at $t_{1}$ (i.e. at the present instant in time) and at $t_{2}$ (namely, when the conjunction between subject and predicate expressed by the minor contingency premise is realized). This does not mean that (1) is always true, and therefore (1) remains a categorical proposition. This means only that (1) is true at the present and at least at another instant in time, in which the minor premise (b) of the auxiliary syllogism is true:

"he [Aristotle] does not call a proposition which is always 〈true〉 categorical - since what is always true is ipso facto necessary - but rather he calls categorical a proposition which can remain a categorical universal affirmative true proposition, even when the contingent affirmative universal proposition, which has been taken along with it, is transformed into a categorical proposition. For in this way the proof by impossibility which he uses to show that this combination is syllogistic is preserved." (in Pr. Anal. p. 189, 1. 33-p. 190, 1. 1, tranl. Mueller 1999b, 100, slightly modified). ${ }^{16}$

The solution given by Alexander is able to solve the problem of the validation of Barbara (and of Celarent) XQ-M and does not imply a revision of the

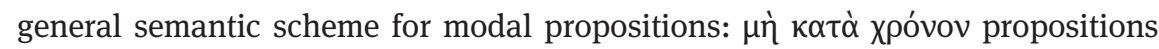
fall under the kind of categorical proposition, since they are true at the present instant in time and they are not (necessarily) always true. In other words, since these propositions are not necessity propositions, there could be instants in time in which they are false; but they are not true only at the present instant in time, but, at least, at two instants in time. From this viewpoint, it is possible to make sense of Aristotle's claim in Pr. Anal. A, 15, 34 a34-b2.

I think that it is important to stress that Alexander does not exclude that a

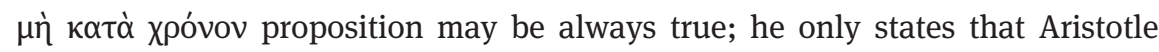
does not say that propositions of this kind are necessity propositions, namely

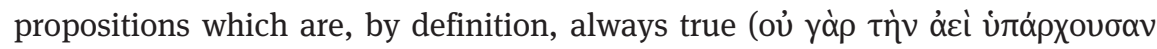

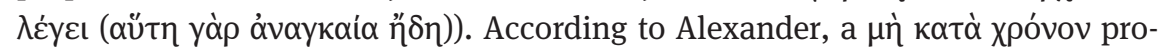
position is a categorical proposition - which is therefore true at the present in-

16 ov̉ yà

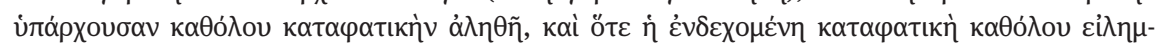

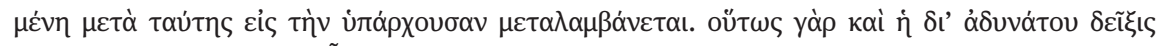

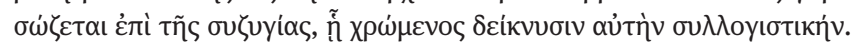


stant in time, by definition of the categorical propositions; but this proposition is also true, when it will be true to say that the predicate, which contingently is said of the subject in the minor premise of Barbara XQ-M, actually holds of this

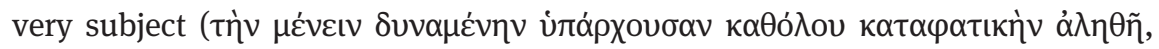

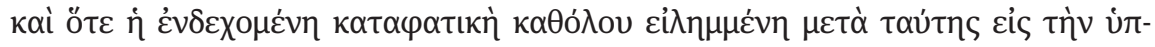

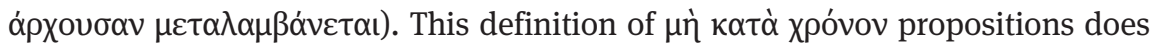
not rule out the possibility that the predicate always holds of the subject - since the definition only states that it holds for at least two instants in time. However, it is rather hard to see which propositions may be true only at a proper subset of the set of all instants in time. ${ }^{17}$ As a consequence, it may be useful to understand the predicative relations that may be expressed in terms of $\mu$ ì $\kappa \alpha \tau \grave{\alpha}$

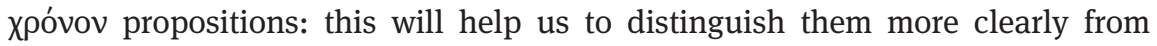
genuine necessity propositions. However, semantic analysis raises some diffi-

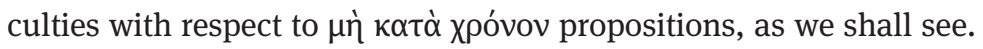

\section{Conclusion: Alexander's semantic attempt to reorder Aristotle's modal syllogistic as a tool to understand the status of $\mu$ nे $k \alpha t \grave{\alpha}$ Xpóvov propositions}

Even though one could plainly grasp the solution Alexander gives to the abovementioned specific problem raised by Barbara XQ-M, it is more difficult to see

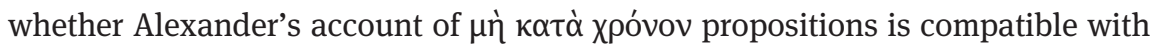
his own general semantic explanation of Aristotle's modal syllogistic. In order to justify this assumption, it is useful to provide a brief presentation of the commentator's semantics. ${ }^{18}$ Alexander is rather explicit on this point and says that terms, which figure in premises and conclusions of syllogisms, fall under the ten categories. ${ }^{19}$

17 Some examples may be the following: (a) "Today some U.S. citizens gave their preference to B. Obama"; (b) "All the students of this class are younger than 20 years of age"; (c) "Some German citizens were born in 1950”, etc. All these examples contain indexical expressions: these propositions do not expand predicative relations among traditional Aristotelian praedicabilia.

18 On Alexander's semantics for modal syllogistic see Gili 2012.

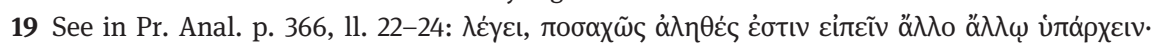

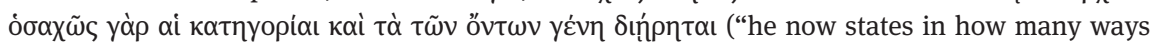


These terms, if they are taken as predicates, are predicated either simpliciter, or as part of their subjects. The predicates, which are predicated simpliciter, are genera, differentiae, propria and definitions, whilst accidents are predicated only partially and not simpliciter. ${ }^{20}$ Following Aristotle (cf. in particular Top. A, 8, 103 b6-19), Alexander thinks that every term which figures in a proposition is either convertible with the other term of the proposition, or not convertible. Let us consider a proposition of the structure:

(iv) A is said of all B.

According to Alexander, B is convertible with A, either because A is the definition of $\mathrm{B}$, or because $\mathrm{A}$ is a proprium of $\mathrm{B}$. If $\mathrm{B}$ is not convertible, either $\mathrm{A}$ belongs to the essence of $\mathrm{B}$ (and in this case it is either a genus or a differentia), or it does not belong to the essence of $\mathrm{B}$, and hence $\mathrm{A}$ is an accident. The text in which this doctrine is presented is the following:

"Everything that is predicated of another thing either does not or does have the same extension as this (when it does, the two are counter-predicated of each other), where what is counter-predicated either is or is not in the essence and the definition of the thing, and if it is in the definition it will be genus or difference, but if not, it will be an accident, since the accident was that which being 'neither definition nor prorpium nor genus' yet holds of the thing - given all of this we could have a categorical syllogism in the first figure based on disjunction as follows:

- Everything that is predicated of another thing has or has not the same extension as this thing

- Everything that is predicated of this thing either as definition, proprium, genus or accident

- Therefore everything that is predicated, is predicated either as definition, proprium, genus or accident.

it is true to say that one thing holds of another, namely in as many ways as the ways in which the categories and the genera of being have been divided" transl. Mueller 2006b, 56).

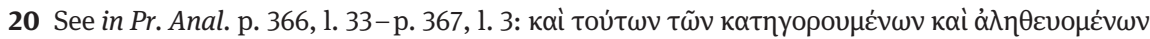

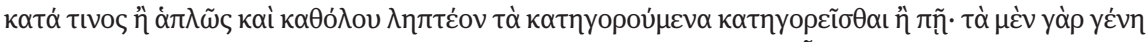

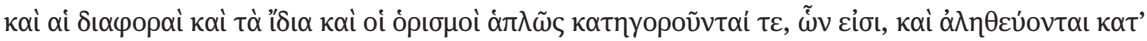

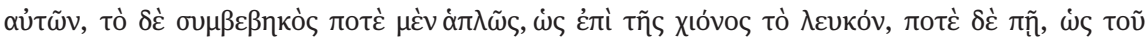
ó $\varphi \theta \alpha \lambda \mu$ oṽ tò $\lambda \varepsilon v \kappa o ́ v$ ("and of these things which are predicated and true of something one should take what is predicated as predicated either without qualification, that is, universally, or in some way. For genera and differentiae and propria and definitions are predicated without qualifications of the things of which they are the genus or differentia or proprium or definition and of which they are true, but an accident is sometimes predicated simply - as with bright in the case of snow - and sometimes in some way, as bright in the case of eye” transl. Mueller 2006b, 56). 
By this conclusion it has been obtained that in every problem what is predicated is either definition, proprium, genus or accident” (in Top. p. 63, 1. $26-$ p. 64, 1. 7, transl. Van Ophuijsen 2001, 68-69, slightly modified). ${ }^{21}$

That which is convertible with the subject and that which belongs to the essence of the subject cannot fail to apply to the items of which the subject is predicated, if the subject is not an accident. These core relations between terms govern, in some sense, the modal propositions which figure in a syllogism. If A is convertible with $\mathrm{B}$ and $\mathrm{A}$ belongs to the essence of $\mathrm{B}$, then (iv) will be plainly a necessity proposition. If $\mathrm{A}$ is not convertible with $\mathrm{B}, \mathrm{A}$ is an accident of $\mathrm{B}$; therefore (iv) will be a contingency proposition (according to the broad meaning of "contingency", which covers both categorical and genuine contingency propositions). The more controversial case is that of propria, which can be converted with their subject, but which do not belong to its essence. I shall argue that it is likely that Alexander has in mind propria as possible candidates for predicates of

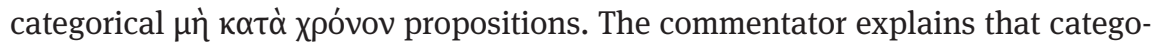

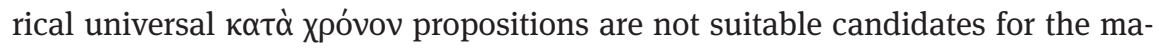
jor premise of Barbara XQ-M, because they may be translated into categorical

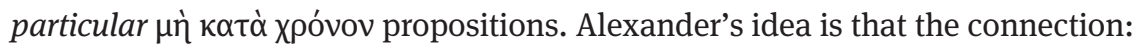

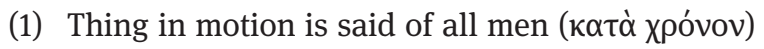

(2) Horse is contingently said of all things in motion

is equivalent to the connection:

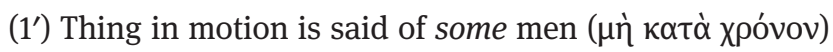

$\left(2^{\prime}\right)$ Horse is contingently said of all things in motion.

This equivalence is motivated by the fact that if A belongs to all B in the present instant in time, it is possible that in another instant in time it does not belong to all B (in our example, it is possible for some men to remain in the same

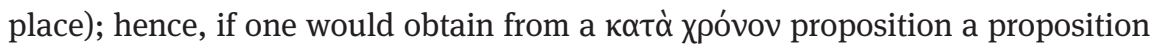
which is not linked to a given instant in time, it is necessary to transform the universal affirmative into a particular one (cf. in Pr. Anal. p. 189, 1l. 13-16: "But

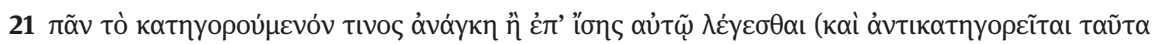

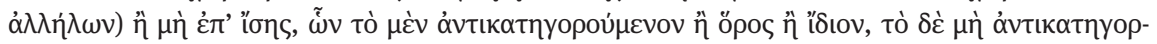

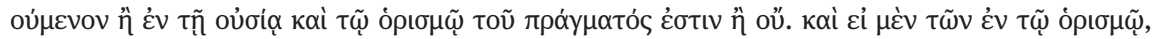

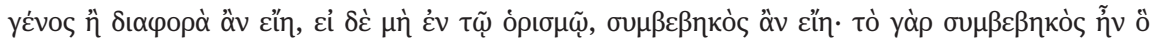

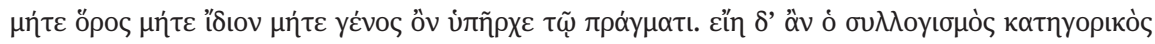

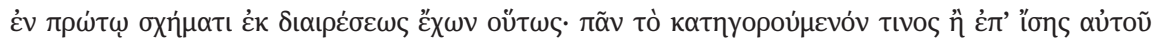

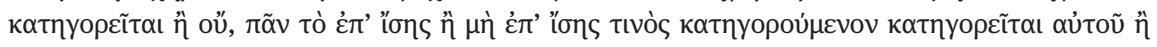

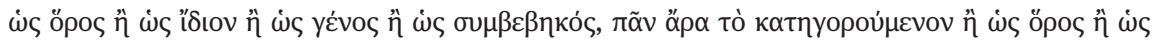

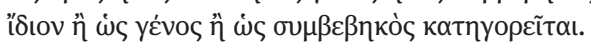


then 〈the premises > cannot be true at the same time if the middle is taken to hold of all of a last term which falls outside the major extreme. For then, the major premiss cannot still be universal affirmative categorical, but it becomes particular”, transl. Mueller, 1999b, 100, slightly modified).22

Now, according to Alexander, this second syllogistic connection (with a categorical particular major premise and a contingency universal minor premise) is plainly not syllogistic, since it has the structure of first figure syllogistic connections, but the major premise is particular and there are no syllogisms of the first figure with a particular major premise (cf. in Pr. Anal. p. 190, 11. 9-11: "for if 〈the categorical major premise〉 is restricted temporally and it changes, it makes the major premise in the first figure particular negative", transl. Mueller 1999b, 101, slightly modified). ${ }^{23}$

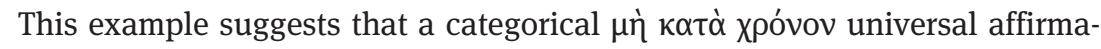
tive proposition cannot have as predicate an accident, which may fail to apply to its subject, and whose relation to the subject could better be described by contingency propositions or by categorical particular propositions. The way out of this puzzle seems to consider a proprium the only candidate for the predicate of propositions of this type, because in them the subject must be convertible with the predicate. Alexander is quite explicit with respect to this aspect, be-

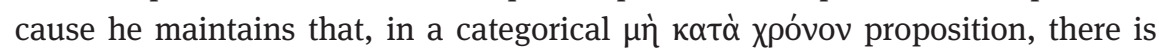
no part of the major extreme term to which the middle term fails to belong (cf.

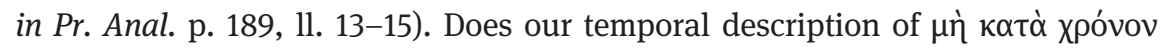
propositions fit with this semantic analysis of these propositions, in terms of Aristotelian praedicabilia? At first glance, it seems that the answer is no, because a proprium always holds of its subject: hence, its inherence could more properly be expanded by a necessity proposition, rather than by a categorical

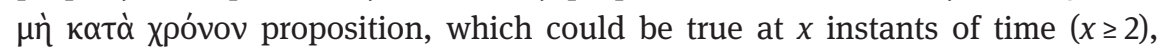
according to our reconstruction. However, it is plain that an accident cannot be

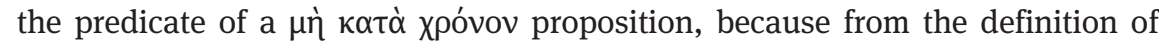
accident we cannot infer that this accident, which actually holds of a subject, will hold also at least in a particular instant in the future. Periodical changes are natural changes, according to Aristotle; and that which is natural belongs to a thing's essence, and is not accidental to the thing. Hence, the predicate of a

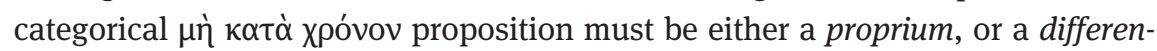

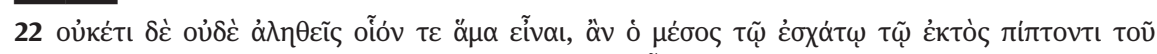

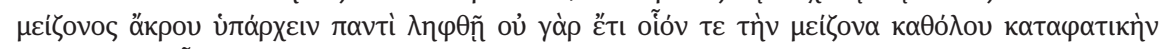

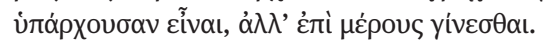

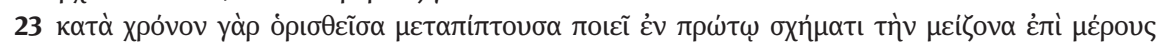

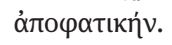


tia, or a definition, or a genus. Aristotle says that if the predicate is either a definition, or a genus (or a differentia, which is similar to a genus), we are faced with essential predication - and that which essentially belongs to something, necessarily belongs to it. Therefore, only propria can be suitable candidates for

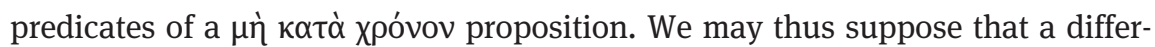
ent kind of proposition has been introduced, in order to distinguish the case of predicates, like propria, which do not belong to the essence of their subjects, even though the temporal analysis of their inherence does not differ from that of predicates of necessity propositions. ${ }^{24}$

This aspect of Alexander's modal theory of predication presents, indeed, many similarities with modern reconstructions which try to justify Aristotle's modal claims on the basis of his theory concerning predicative relations. ${ }^{25}$ To claim that these reconstructions offer a suitable framework, even for the interpretation of Alexander's modal syllogistic, goes beyond the aim of this paper. But I believe that the particular aspect that the present essay has touched upon may offer a useful test case for future research, which will examine this interesting theme.

\title{
Bibliography
}

\author{
Primary sources \\ Pr. Anal. = Aristotle's Prior and Posterior Analytics, a revised text with introduction and com- \\ mentary by W. D. Ross (Oxford: Clarendon Press), 1949.
}

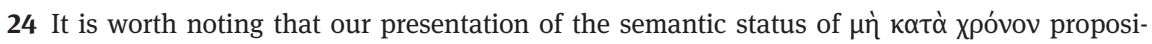
tions has shown that in these propositions the predicate is said of the subject in a stronger sense than in plain categorical propositions. M. Malink's analogous attempt at expanding Aristotle's modal syllogistic on the basis of Aristotle's semantics has reached similar conclusions with respect to the minor categorical premise of a Barbara NX-N (cf. Malink 2006, 100). For Malink 2006, 97, there are two core relations among terms: essential predication (which exists between a genus and its subpecies, or between a definition and its subjects) and a plain accidental predication (which exists among one of the four praedicabilia and their subjects). Malink assumes that if $a$ is essentially predicated of $b$, and $b$ is accidentally predicated of $c$, then $a$ is essentially predicated of $c$ (cf. Malink 2006, 100, ax4): this assumption is made in order to justify Aristotle's claim about the validity of Barbara NX-N. Within Malink's reconstruction, however, $b$ cannot but be a substance term, and $c$ cannot but be a subspecies of it; therefore, the minor premise of Barbara NX-N also expresses an essential predication. In my reconstruc-

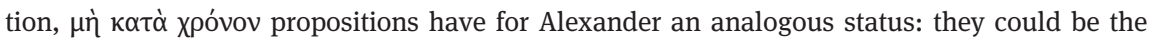
expression of essential predications in the above sense, but they could also have as one of their terms a proprium; nevertheless, accidents cannot figure as terms of these propositions.
\end{abstract}

25 Cf. in particular Patterson 1989, Patterson 1995, Thom 1996, Thom 2003, 1-20, Malink 2006. 
Top. = Aristotelis Topica et Sophistici Elenchi, recensuit brevique adnotatione critica instruxit W. D. Ross (Oxford: Clarendon Press), 1958.

in Pr. Anal. = Alexandri Aphrodisiensis in Aristotelis Analyticorum Priorum librum I commentarium, edidit Maximilien Wallies (Berolini: Typis G. Reimeri), 1883.

in Top. = Alexandri Aphrodisiensis in Aristotelis Topicorum libros octo commentaria, edidit Maximilien Wallies (Berolini: Typis G. Reimeri), 1891.

Secondary sources

Angelelli, Ignacio - Cerezo, Marìa (eds.). 1996. Studies on the History of Logic Proceedings of the III. Symposium on the history of logic, Berlin-New York: W. De Gruyter.

Barnes, Jonathan (ed.). 1984. The Complete Works of Aristotle. Volume 1. The Revised Oxford Translation, Princeton: Princeton University Press.

Barnes, Jonathan - Bobzien, Suzanne - Flannery, Kevin L. - Ierodiakonou, Katarina (eds.). 1991. Alexander of Aphrodisias. On Aristotle Prior Analytics 1.1-7, translated with introduction and commentary by J. Barnes, S. Bobzien, K. L. Flannery, K. lerodiakonou, London: Duckworth.

Becker, Albrecht. 1933. Die aristotelische Theorie der Möglichkeitsschlüsse. Eine logisch-philologische Untersuchung der Kapitel 13-22 von Aristoteles' Analytica Priora, Berlin: Junker und Dünnhaupt.

Bobzien, Susanne. 1986. Die stoische Modallogik, Würzburg: Königshausen und Neumann.

Bobzien, Susanne. 1998. Determinism and Freedom in Stoic Philosophy, Oxford: Clarendon Press.

Flannery, Kevin L. 1995. Ways into the Logic of Alexander of Aphrodisias, Leiden-New YorkKöln: E. J. Brill.

Frede, Michael. 1974. Die stoische Logik, Göttingen: Vandenhoek \& Ruprecht.

Gili, Luca. 2011a. La sillogistica di Alessandro di Afrodisia. Sillogistica assertoria e sillogistica modale nel commento agli Analitici Primi di Aristotele, Hildesheim-Zürich-New York: Georg Olms.

Gili, Luca. 2011b. "Boeto di Sidone e Alessandro di Afrodisia sulla sillogistica aristotelica," Rhenisches Museum für Philologie 154(3-4): 375-397.

Gili, Luca. 2012. "Alexander of Aphrodisias' solution to the puzzle of the two modal Barbaras: a semantic approach," Documenti e Studi sulla Tradizione Filosofica Medievale XXIII: $35-64$.

Hintikka, Jaakko. 1959. “An Aristotelian Dilemma,” Ajatus, 22: 87-92.

Hintikka, Jaakko. 1973. Time and Necessity. Studies in Aristotle's Theory of Modality, Oxford: Clarendon Press.

Johnson, Fred. 1989. “Models for Modal Syllogisms,” Notre Dame Journal of Formal Logic 30: 271-284.

Lee, Tae-Soo. 1984. Die griechischen Tradition der aristotelischen Syllogistik in der Spätantike. Eine Untersuchung über die Kommentare zu den Analytica Priora von Alexander Aphrodisiensis, Ammonius und Philoponus, Göttingen: Vandenhoeck \& Ruprecht.

Łukasiewicz, Jan. 1957. Aristotle's Syllogistic from the Standpoint of Modern Formal Logic, Oxford: Clarendon Press.

Maier, Heinrich. 1900, Die Syllogistik des Aristoteles. Zweiter Teil. Die logische Theorie des Syllogismus und die Entstehung der aristotelischen Logik. Zweite Haelfte. Die Entstehung der aristotelischen Logik, Tübingen: H. Laupp'sche Buchhandlung.

Malink, Marko. 2006. "A Reconstruction of Aristotle's Modal Syllogistic," History and Philosophy of Logic 27: 95-141. 
Mariani, Mauro. 2005. "Sillogistica modale e teorie della predicazione," Teoria (Pisa: Ets) XXV/2: 131-154.

McCall, Storrs. 1963. Aristotle's Modal Syllogisms, Amsterdam: North-Holland Publishing Company.

Mignucci, Mario. 1969. Aristotele. Gli Analitici Primi, traduzione, introduzione e commento di M. Mignucci, Napoli: Luigi Loffredo editore.

Mignucci, Mario. 1996. “Aristotle’s Theory of Predication,” in: Angelelli-Cerezo 1996, 1-20.

Moraux, Paul. 2001. Der Aristotelismus bei den Griechen. Von Andronikos bis Alexander von Aphrodisias. Drittter Band: Alexander von Aphrodisias, hrsg. von J. Wiesner, Berlin-New York: Walter De Gruyter.

Mueller, Ian. 1999a. Alexander of Aphrodisias. On Aristotle, Prior Analytics 1.8-13, translated by Ian Mueller with Josiah Gould, London: Duckworth.

Mueller, Ian. 1999b. Alexander of Aphrodisias. On Aristotle, Prior Analytics 1.14-22, translated by Ian Mueller with Josiah Gould, London: Duckworth

Mueller, Ian. 2006a. Alexander of Aphrodisias. On Aristotle, Prior Analytics 1.23-31, translated by lan Mueller, London: Duckworth.

Mueller, Ian. 2006b. Alexander of Aphrodisias. On Aristotle, Prior Analytics 1.32-46, translated by lan Mueller, London: Duckworth.

Patterson, Richard. 1989. "The Case of the Two Barbaras," Oxford Studies in Ancient Philosophy VII: $1-40$.

Patterson, Richard. 1995. Aristotle's Modal Logic. Essence and Entailment in the Organon, Cambridge (UK): Cambridge University Press.

Sainati, Vittorio. 1981. "La sillogistica modale aristotelica: problemi storici e teorici," Teoria (Pisa: Ets) I/2: 25-70.

Sainati, Vittorio. 1983. "Per una nuova lettura della sillogistica aristotelica," Teoria (Pisa: Ets) III/2: 53-66.

Schmidt, Klaus J. 1989. "Eine modal-prädikatenlogische Interpretation der modalen Syllogistik des Aristoteles," Phronesis XXXIV: 80-106.

Sharples, Robert W. 1987. "Alexander of Aphrodisias: Scholasticism and Innovation,” in: Aufstieg und Niedergang der Römischen Welt, Teil II, Band 36.2: 1176-1243, Berlin-New York: Walter De Gruyter.

Striker, Gisela. 2009. Aristotle. Prior Analytics. Book I, translated with an introduction and commentary by G. Striker, Oxford: Clarendon Press.

Thom, Paul. 1996. The Logic of Essentialism. An Interpretation of Aristotle's Modal Syllogistic, Dordrecht: Kluwer Academic Publishers.

Thom, Paul. 2003. Medieval Modal Systems. Problems and Concepts, Aldershot: Ashgate.

Tredennick, Hugh. 1938. Aristotle. Prior Analytics, London-Cambridge (Mass.): Harvard University Press.

Van Ophuijsen, Jan M. 2001, Alexander of Aphrodisias. On Aristotle, Topics 1, translated by J. M. Van Ophuijsen, London: Duckworth.

Volait, Georges. 1907. Die Stellung des Alexander von Aphrodisias zur aristotelischen Schlusslehre, Halle: Druck von Ehrhardt Karras.

Wieland, Wolfgang. 1966. "Die aristotelische Theorie der Notwendigkeitsschlüsse," Phronesis XI: 35-60.

Wieland, Wolfgang. 1972.“Die aristotelische Theorie der Möglichkeitsschlüsse,” Phronesis XVII: 124-152.

Wieland, Wolfgang. 1975. "Die aristotelische Theorie der Syllogismen mit modal gemischten Prämissen," Phronesis XX: 77-92. 